\title{
Controlled-Release Fertilizers for Florida Citrus Production 1
}

\section{Tom Obreza and Bob Rouse ${ }^{2}$}

In the new age of Florida citrus production, Best Management Practices to protect water quality are being considered across the state. Growers have been encouraged to carefully consider nitrogen $(\mathrm{N})$ fertilizer rates, application schedules, and irrigation management in their groves. Nitrogen sources have received little attention because most managers are accustomed to using water-soluble fertilizers like ammonium nitrate, ammonium sulfate, and urea. Synthetic controlled-release fertilizers (CRFs) have existed commercially for more than 35 years, but other than use in young-tree fertilizer blends, Florida citrus growers have avoided them due to high cost and lack of production experience.

The first marketed CRFs were $\mathrm{N}$ sources only (sulfur-coated urea for example). The technology has now expanded to include potassium, phosphorus, and some micronutrients. However, $\mathrm{N}$ still dominates controlled-release products because it is a highly-leachable nutrient, especially in sandy Florida soils where rainfall is abundant.

\author{
Why would a citrus grove manager be \\ interested in CRFs? Answers to this question include \\ increased efficiency of applied $\mathrm{N}$ (equal or better \\ production at a lower $\mathrm{N}$ rate), lower application \\ frequency (fewer trips needed through the grove), a \\ large number of resets to manage, or environmental \\ advantages (especially on the central Florida ridge \\ where nitrogen management BMPs are in place).
}

Why might a manager be wary of CRFs? As mentioned, they have traditionally cost more than water-soluble fertilizers. There also may be a lack of faith about their performance in the field. Managers used to applying dry fertilizer at least three times per year would probably ask "Can I really apply fertilizer only once a year to my sandy soil and provide all of the necessary nutrition required for maximum production?" Most growers would require proof that one annual application of CRF would actually work in their groves before using it on a large scale.

Some citrus growers may have experience with older controlled and slow-release fertilizers like

1. This document is SL-214, a fact sheet of the Soil and Water Science Department, Florida Cooperative Extension Service, Institute of Food and Agricultural Sciences, University of Florida. Published: January 2004. Please visit the EDIS Web site at http://edis.ifas.ufl.edu.

2. Tom Obreza, professor, Soil and Water Science Department, and Bob Rouse, associate professor, Horticultural Sciences, Southwest Florida Research \& Education Center, Immokalee, Florida Cooperative Extension Service, Institute of Food and Agricultural Sciences, University of Florida, Gainesville, FL 32611-0290.

The use of trade names in this publication is solely for the purpose of providing specific information. UF/IFAS does not guarantee or warranty the products named, and references to them in this publication does not signify our approval to the exclusion of other products of suitable composition.

The Institute of Food and Agricultural Sciences (IFAS) is an Equal Opportunity Institution authorized to provide research, educational information and other services only to individuals and institutions that function with non-discrimination with respect to race, creed, color, religion, age, disability, sex, sexual orientation, marital status, national origin, political opinions or affiliations. U.S. Department of Agriculture, Cooperative Extension Service, University of Florida, IFAS, Florida A. \& M. University Cooperative Extension Program, and Boards of County Commissioners Cooperating. Larry Arrington, Dean 
sulfur-coated urea, methylene urea, and IBDU. These materials have occasionally been bulk-blended with water-soluble $\mathrm{N}$ and other nutrients to make a longer-lasting fertilizer mixture. They release $\mathrm{N}$ by slowly dissolving, decomposing, or in the case of sulfur-coated urea, seeping through cracks in the coating. Growers have less experience with newer CRF sources that use resin, polymer, or plastic coatings because along with higher technology comes higher cost. Manufacturing a synthetically-coated product requires sophisticated equipment and a high level of quality control, so these fertilizers have usually been directed towards high-end markets like ornamental horticulture and homeowners.

Beginning in 1995, we evaluated several coated, controlled-release fertilizers manufactured by The Scotts Company for their effects on mature orange tree growth, fruit yield, and juice quality. The analysis of each material in our trial was 16-5-16, where nutrients were contained inside prills covered with either a resin or a polymer coating. The Scotts Company refers to these as Agrocotes ${ }^{\circledR}$. One was a proprietary resin-coated N-P-K technology and the other a patented Poly-S® N and K technology.

Nutrients are released from the prills following water vapor penetration through the coating, dissolution of the nutrients inside, and gradual diffusion of the soluble nutrients back out into the soil.

We initiated our experiment on 5-year-old bearing Hamlin orange trees in a commercial citrus grove with standard cultural practices and ran it for 6 years (one initial baseline yield year and 5 treatment years). We applied resin-coated and Poly-S® coated CRF treatments in April of each year at 45 and $90 \mathrm{lbs}$ N/acre. We also applied a 50-50 mixture of these two materials at $90 \mathrm{lbs}$ N/acre. Our standard treatment consisted of water-soluble fertilizer applied in April, July, and October at total rates of 45, 90, and $180 \mathrm{lbs}$ N/acre. Fertilizers were applied by hand under the tree canopy (Fig. 1), and remained there following several heavy rain events during the first 2 months after application (Fig. 2). We measured boxes per tree and pounds solids per box for each treatment from which we calculated the pounds solids per tree yield. To measure the long-term effects of the fertilizer treatments, we added the five yearly yields together and expressed production as " 5 -year cumulative pounds solids per tree."

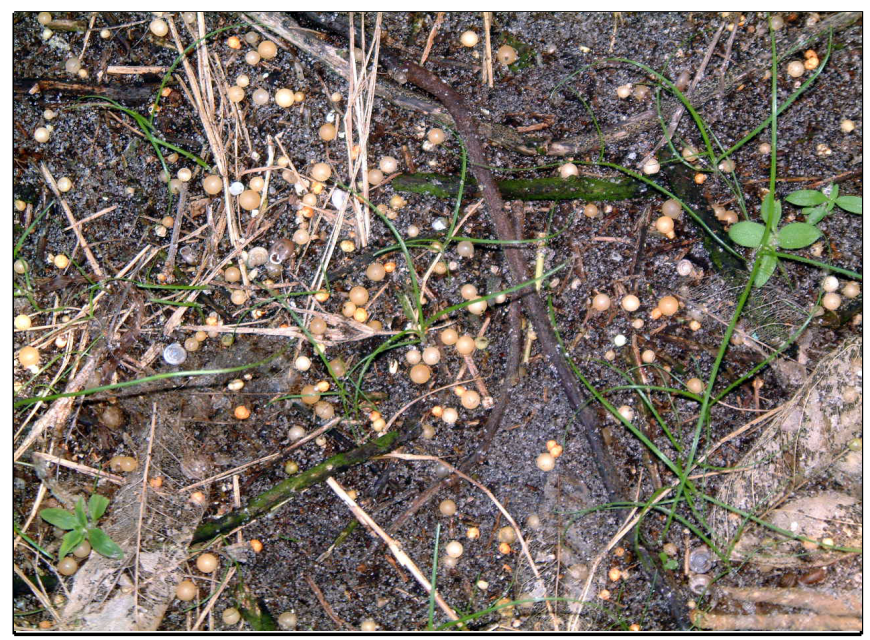

Figure 1. Fertilizer shown under the tree canopy following mechanical application.

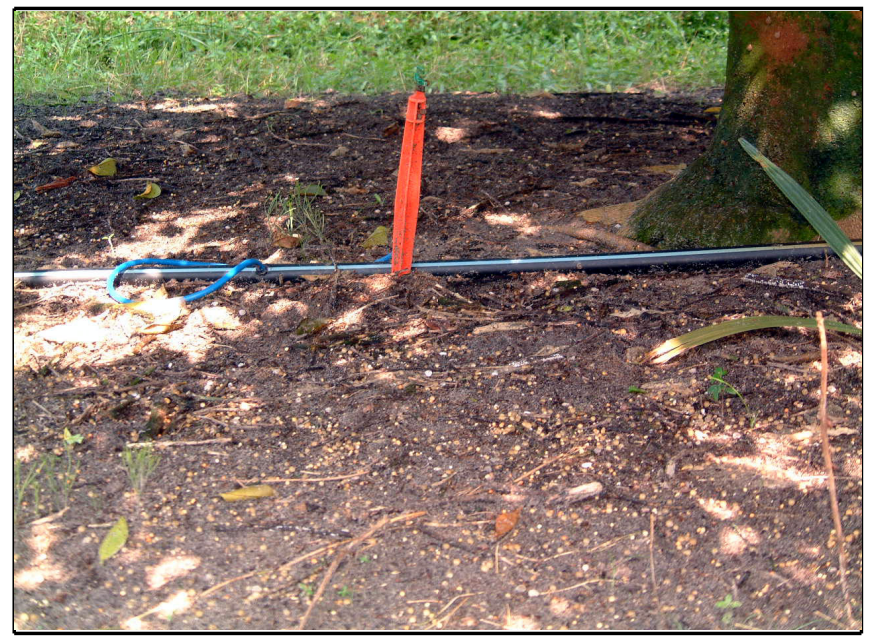

Figure 2. Fertilizer remains under the tree canopy following several heavy rain events during the first two months after application.

Yield response to water-soluble $\mathrm{N}$ fertilizer was described by a gently-sloping curve that reached its maximum at 77 pounds solids/tree (Fig. 3).

Description of the $\mathrm{N}$ rate response for CRFs was limited because the resin and Poly-S coated sources were applied at only two rates and the mixture was applied at only one rate. Still, the increased $\mathrm{N}$ fertilizer efficiency provided by the controlled-release sources was evident by the sharp increase in yield as $\mathrm{N}$ rate increased from 45 to $90 \mathrm{lbs} / \mathrm{acre}$ (Fig. 3). It was apparent that the citrus trees responded more strongly to increasing rates of CRF compared with the water-soluble source. 


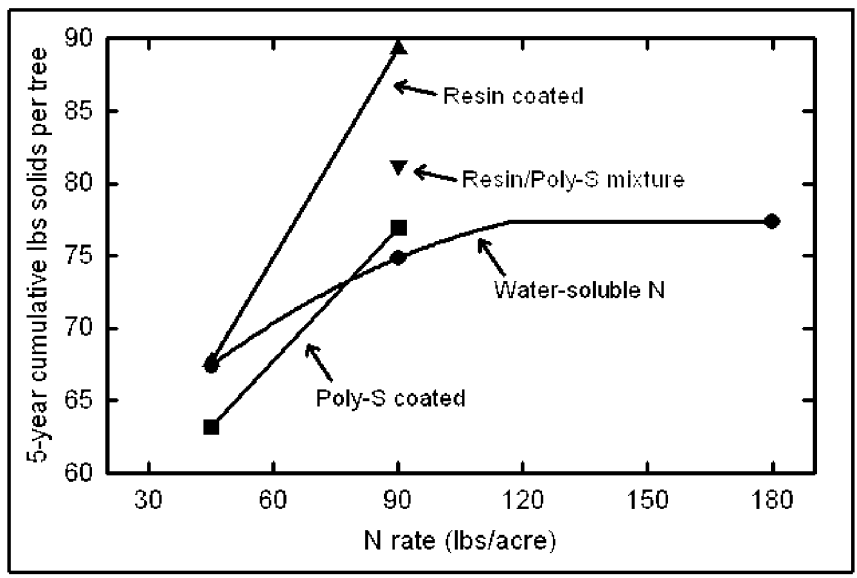

Figure 3. Response of Hamlin orange trees to controlled-release and water soluble fertilizers.

Citrus trees responded to the four $\mathrm{N}$ sources applied at $90 \mathrm{lbs}$ N/acre in this order: resin-coated, resin/Poly-S mixture, Poly-S coated, and water-soluble. The resin-coated material yielded 15 pounds solids per tree more than water-soluble $\mathrm{N}$ in 5 years at the $90-1 b$ rate. The resin/Poly-S mixture yielded about 7 pounds solids per tree more than the standard treatment. The CRFs performed better when applied once per year at $90 \mathrm{lbs}$ N/acre than water-soluble fertilizer applied three times per year at $180 \mathrm{lbs}$ N/acre.

The resin/Poly-S mixture we evaluated in this trial served as the forerunner to the suite of materials that The Scotts Company now markets as CitriBlen®. This fertilizer is the first material composed of mostly coated nutrients that is made and marketed specifically for mature Florida citrus as a one application per year N-P-K fertilizer. Field trials are now under way in several commercial groves to evaluate the performance of CitriBlen in large production blocks and compare it with standard water-soluble fertilization practices. 